\title{
VIOLENCE AGAINST WOMEN DURING COVID-19 IN BANGLADESH
}

\author{
Md. Mahabub Chowdhury \\ Lecturer \\ Department of Development Studies \\ Hajee Mohammad Danesh Science and Technology University \\ Dinajpur-5200, Bangladesh \\ E-mail: mahabubds.hstu@gmail.com
}

\begin{abstract}
COVID-19 has become one of the biggest humanitarian crises affecting millions of lives around the world. Bangladesh is also affected by the COVID-19 crisis. Society, health, and economic sectors of Bangladesh are affected by this pandemic. Violence against Women is also common in Bangladesh. This study discusses the trends of violence against women in Bangladesh during the COVID-19 pandemic. The prevailing gender norms, patriarchy, and socio-economic factors made women of Bangladesh vulnerable to different forms of gender-based violence. Women face different types of gender-based violence such as rape, domestic violence, dowry-related violence, sexual harassment, and stalking. The objective of the study is to find out the trends of violence against women during COVID-19, underlying factors behind such acts, and the consequences of such violence on women's lives. The study is done using qualitative research techniques. Indepth interview, Key Informant Interview (KII), document analysis techniques were used to collect data. This study found that socio-cultural factors and prevailing gender norms played a significant role in the spike of violence against women during the pandemic causing extreme social, psychological, economic, and health harm to women.
\end{abstract}

Keywords: Bangladesh, COVID-19, Gender, Violence against Women (VAW).

JEL Classification Codes: K42, K38, N35.

\section{INTRODUCTION}

Equal status, position, and safety of men and women are very important for a dignified, equal, and safe society. This is also important for social and economic development and progress. Violence against women (VAW) is a threat towards ensuring equal status, position, safety for men and women. The condition of violence against women in Bangladesh has been alarming over the years. There have been measures in place to combat such acts in Bangladesh. This type of incident is not only limited to the four walls or personal relations but it occurs also in the greater community and all spheres of lives. The history of the Indian sub-continents shows that women have always been subjected to be the victim of gender-based violence. Issues like extreme seclusion, the practice of Sati (Sati-Daho), and domestic violence were some of the common forms of violence that women of Indian Sub-continents faced. In recent years, domestic violence like dowry violence, lack of social and economic opportunities, rape, sexual 
harassment, and killing have become daily incidents. As a result, it has become difficult to build and continue a safe, equitable, dignified, and prosperous society for all irrespective of individuals' gender identities.

Violence against women in Bangladesh is not new. Rather, women of this country have been subjected to be the victim of violence in different spheres of lives. Initially, poor and rural women are thought of as the major victim of such violence. Recent research suggests that women belonging to all social and economic classes, religions, ages, and regions face violence. Violence against women is getting huge media coverage in recent years though the number is increasing day by day. Added to this, the huge availability of the internet and social media has made it more dangerous for women of being subjected to face cyber-crime. The COVID-19 crisis has affected the lives of everyone (Shuvro \& Talukder, 2020). The pandemic has an impact on all sectors of the country such as the economy, health, education, livelihood, production. There are important measures in places such as health and safety protocol, social distancing, physical distancing, prolonged lockdown, and limited mobility leading to the enormous impact of individuals' way of living in social and economic spheres. All these changes have also an impact on the safety and security of women. During the ongoing COVID-19 pandemic domestic violence and rape against women and children have increased in Bangladesh (International Federation for Human Rights, 2020). There has been a lot of study on violence against women in Bangladesh. Different researchers and organizations put their efforts to focus on how and to what extend violence against women is taking place. It is important to understand how things are related to genderbased violence in the COVID-19 crisis. Therefore, the current study contributes to the vast area by adding an analysis of trends of violence against women in the context of the pandemic. This study also aims at providing a consolidated picture of such trends.

Theories established in fields like sociology such as exchange theory and resource theory and gender studies such as power and control theory, social learning theory, intersectionality, and feminist theory show how different factors influence women's position within the society leading them towards vulnerability and insecurity. The current study also focuses on this theoretical dimension especially intersectionality to understand and analyses violence against women in the COVID-19 situation. Intersectionality is an analytical framework shows that how multiple factors such as sex, race, gender, sexuality, religion, and class be can both empowering and oppressing for an individual creating either privilege or discrimination (Runyan, 2018). Women's position within society is often influenced by the existing social norms, economic class, and gender norms and values. Other important factors such as their education, religious identity, and geographical location such as living in either rural or urban areas also influence women's position within the society. As women live in a patriarchal society with rigid gender discrimination, their severity and vulnerability due to gender-based violence in a pandemic situation need to be addressed. This will not only allow us to understand how, why and to what extent women are being the victim of violence in a crisis but also provide us with the underlying sufferings in terms of social, economic, psychological, and health consequences of violence against women. The primary objective of this study is to find out how and to what extent women are experiencing different forms of violence against women. This study also intends to find out what are the factors influencing violence against women in the middle of a major crisis instigated by the COVID-19 pandemic. 


\section{SIGNIFICANCE OF THE STUDY AND RELEVANT SCHOLARSHIP}

The definition of violence against women covers a wide range of issues and factors. Development practitioners and women's rights activist groups have been focusing on the multifaceted aspects in different contexts. Added to this, International Treaties and Human Rights Organizations have also clarified violence against women and how it is affecting women's lives.

Hossain, Imam, and Khair (2001) state that violence against women is the outcome of perceived differences of power wealth, status, and prestige that men and women ascribe along with the norms of patriarchy. It refers to several acts such as sexual harassment, rape, murder, physical abuse, psychological abuse, sex trafficking, forced pyrography, and many more. According to Crowell and Burgess (1996), the term 'Violence against Women' broadly is aggressive behavior that disproportionately and adversely affects women.

The United Nations (UN) (2016) has defined Violence against Women (VAW) as any act of gender-based violence that results in and sometimes is likely to result in physical, sexual, or mental harm and suffering such as threats of such acts related to physical, sexual, or mental harm and suffering, coercion, or arbitrary deprivation of liberty occurring in public or private life to women. In terms of physical, psychological, sexual, and economic aspects violence against women is widespread (Hossen, 2014). Violence against women and girls is regarded as one of the most widespread and systematic human rights violations (Relief Web, 2017). According to a UN Women's 2021 global review quoted in UN Women (2021), 35\% of women have experienced physical and sexual intimate partner violence or non-partner sexual violence around the world (UN Women, 2021).

Over the years, researchers have been studying different types of violence. According to Mahtab (2012), violence against women can be as follows:

- Domestic Violence

- Sexual Assault and Harassment

- Rape

- Dowry Violence

- Acid Throwing/ Acid Violence

- Forced Prostitution

- Women Trafficking

She has also discussed 'Honour Killing' and 'Female Genital Mutilation (FGM) in her writing and how this act harms women's personal, familial, social, economic lives.

A critical analysis of different policy documents, reports, data, and national action plan of Bangladesh on violence against women show physical violence and abuse, sexual violence, psychological violence, acid attack, and economic violence as some of the major acts of violence that women face in Bangladesh. All these different forms of violence can be broadly categorized as physical violence, psychological abuse, and sexual violence.

Women face and experience these acts of violence during their whole span of lives in different forms and magnitudes.

The study by Ellsberg and Heise (2005) shows a cyclical nature of violence against women in society. According to their analysis which is also adapted and analyzed by UN Women (2010), the life cycle of violence against women is as follows: 
- Pre-birth: Pre-natal Sex Selection

- Infancy: Female Infanticide, Neglect (Health Care, Nutrition)

- Childhood: Child Abuse, Child Marriage, Malnutrition, FGM/C, Trafficking

- Adolescents: Femicide, FGM/C, Forced Marriage, Forced Sex, Intimate Partner Violence, Dating Violence, Sexual Harassment, Trafficking

- Reproductive Age: Femicide, Dowry-related Violence, Intimate Partner Violence, Nonpartner Sexual Assault, Honor Crimes, Sexual Harassment, Political Violence, Economic Abuse, Trafficking

- Elderly: Elder Abuse/Widow Abuse, Economic Abuse

The unprecedented crisis of COVID-19 that Bangladesh is facing has been described as the greatest public health challenge in a generation. Bangladesh is the third most affected country in South Asia, after India and Pakistan (Corona Info, 2020). To protect the population, the government of Bangladesh has taken many steps including social distancing measures, travel and entry restrictions, COVID-19 dedicated hospitals, and national helplines. Added to this, health officials and administration are also working on implementing certain rules and regulations to protect the population from being infected. COVID-19 is much more than a health crisis (United Nations Development Programme, 2020). All sectors are being pushed towards the devastating impact. In the case of Bangladesh, the Economy is one of the most hit sectors.

According to the Bangladesh Institute of Development Studies (BIDS), for the last few months, because of the COVID-19, household and individual level earnings in Bangladesh with around $13 \%$ of people have become unemployed, and lower and middle-income classes have been facing and experiencing a notable drop in income (The Financial Express, 2020). As a result, the disposable income of the country's people is following a declining trend and the national poverty is forecasted to increase by $25.13 \%$, according to the same survey of BIDS.

The COVID 19 crisis has caused a reduction of exports by $16.93 \%$, imports by $17 \%$, and also a decline of average revenue for all small and medium enterprises (SMEs) by $66 \%$ in 2020 compared to 2019 whereas only remittance inflow has seen an $11 \%$ increase in 2020 (Latifee \& Hossain, 2020). Added to this education of millions around the country has been seriously disrupted. The health, social and economic sectors are in the vulnerability context caused by the COVID-19 crisis. The situation of violence against women in the context of this global crisis is another important issue raised by the international, national, and local development community and organizations. Different studies have been concentrating on the issues. The deeper analysis of the situation requires a comparative discussion on the trends of violence against women between before and during the COVID-19 situation to have a comprehensive picture.

An analysis of different reports shows a devastating situation of violence against women worldwide over the last few years. UN (2016) claims that 1 in 3 women and girls are subjected to sexual or physical violence perpetrated by their intimate partners most of the time (The Daily Star, 2019). According to the same United Nations (UN) data, 750 million women and girls alive today had been forced into underage marriage and $48 \%$ of women who are married or in a relationship are not allowed to make decisions about contraceptives, sexual relations, or healthcare around the world. According to a recent report by World Health Organization (WHO) which was prepared after analyzing the data on violence against women in 61 countries and areas between the years 2000 and 2018 states that worldwide one in three women is subjected to physical or sexual violence during her lifetime (Prothom Alo, 2021). 
The situation here in Bangladesh is equally devastating. The condition is also shown by many researchers. At least 300000 children were trafficked to India and $6 \%$ of maternal mortality is caused by suicide and death of women due to rape, murder after rape, and pregnancy as a result of rape (Mahtab, 2012). The analysis of the World Health Organization (WHO) quoted in a news report says that $50 \%$ of women (between 15-49 years old) have experienced physical or sexual violence by their partner in their lifetime (Prothom Alo, 2021). This has made Bangladesh one of the top-ranking countries in violence against women by an intimate partner, the report of WHO says. Domestic violence is prevalent in Bangladesh as well. According to a report of the Bangladesh Bureau of Statistics (2011) analyzed in a news report, 87\% of women face violence at home (Dhaka Tribune, 2017). Another study conducted by Action Aid Bangladesh and Jatiyo Nari Nirjaton Protirodh Forum quoted in a news report suggest that $66 \%$ of women experience violence at their house (Dhaka Tribune, 2018).

The information gathered by Odhikar (2020), shows the trends of different types of violence against women of the last five years before the COVID-19 crisis. It shows that, from 2015 to 2019, 1050 women and girls were the victim of sexual harassment and stalking, 377 were attacked due to protest against stalking and sexual harassment, 4044 were raped, 1163 were gang-raped, 217 were killed after being raped, 26 women and girls committed suicide after being raped, 463 were killed due to dowry related violence, 467 were physically abused and 24 committed suicide due to dowry related violence.

The study also shows that the number of violence against women has increased during the COVID-19 crisis. According to Human Rights Watch (2020) Women and girls in Bangladesh are facing increased domestic violence during the COVID-19 pandemic. There is a $24 \%$ up of the incidents of gender-based violence in Bangladesh during the COVID-19 pandemic (Dhaka Tribune, 2020c). All these analyses and works indicate the existing severity of violence against women in recent years and the spike in the context of the COVID-19 crisis. Understanding the trends of violence against women during the COVID-19 crisis is of immense importance for identifying the underlying factors of violence against women and how women experience vulnerability and sufferings even in the context of a pandemic. There has been extensive study concerning violence against women in Bangladesh. But, this study exclusively focuses on the trends of such violence against women in the context of COVID-19 and brings light on narratives of the subjective experience of victim women to draw a consolidated picture of violence against women in pandemic crisis. This will help us to understand how violence against women during a pandemic can lead to extreme social, economic, psychological, and health sufferings and vulnerability. It will also help in identifying the opportunities and areas of future research on this issue.

\section{RESEARCH METHODOLOGY}

Research methodology is the systemic way of solving the research problem and how the research is done. The research method is dependent on the nature of the research problem, research subject, and objectives of the study along with assumption, logic, and rationale behind them. This study aims to review and investigate the trends of violence against women during the COVID-19 crisis along with the narrative of the subjective experience of women victims of such violence. As violence against women is a development agenda and often connected with social justice and social change which is similar to feminist research methodology, this study is qualitative. In doing so, this study aims to provide an in-depth and interpreted understanding of 
study participants by involving their experiences, perspectives, and histories as the victim of violence against women in the middle of the COVID-19 crisis.

\section{Primary Data}

Qualitative research techniques such as in-depth interviews, key informant interviews (KII), and document analysis methods were used for collecting data from primary sources. The primary data was collected from December 2020 to February 2021. Primary data was collected following a standard research ethical guideline and consents of the respondents were taken accordingly. As violence against women is a sensitive issue, the identity of the respondents will be confidential.

\section{Secondary Data}

Secondary data played a significant role in this study. Journal articles, research reports, reports of different organizations, news reports on violence against women during COVID-19 are the secondary source of data in this study.

\section{Population}

As this study intends to study the trends of violence against women during COVID-19, women who have experienced such violence during the pandemic period and their families are the populations of this study.

\section{Sampling Procedure}

The Purposive sampling method has been used in this study. Purposive sampling is a compatible method to study a small part of the target population. The number of victims of violence against women is large. In the middle of the COVID-19 crisis, it is also difficult to reach a large population maintaining health measures. Added to this, violence against women is a sensitive issue and only a handful of people are available to discuss such sensitive topics because of cultural, social, and legal factors. Therefore, the purposive sampling method has been employed to get profound insights regarding the underlying factors of violence against women, sufferings of victims, and socio-cultural implications due to violence against women. Considerations like representation of victim experiencing different types of violence, having expertise on particular issues related to violence against women (in case of selection of respondents for the KII), and time, distance, communication facilities, availability, and consent were given an upper hand in the selection of the respondents for this study.

\section{Data Collection Techniques In-depth Interview}

Ten women who are the victim of violence against women were interviewed using an in-depth interview method to understand how women have experienced violence against women and the sufferings they are going through. In addition to this, 5 individuals from the families of the victim were interviewed using the same in-depth interview method. Due to COVID-19, in-depth interviews were conducted following strict safety and health measures. Respondents were interviewed and their answers were written and later interpreted and transcripted for the analysis.

\section{Key Informant Interview (KII)}

Five respondents who work on women's rights and violence against women issues were interviewed using the Key Informant Interview (KII) method. KII was used to understand 
insights of violence against women from expert perspectives and narratives. This method has been well-known for getting a detailed narrative of ins and outs of a particular problem from a person who has expertise on that particular issue.

\section{Document Analysis}

The document analysis method has been used to gather, collect, and analyze the available data and analysis regarding violence against women, factors influencing violence against women, and women's vulnerability instigated by different forms of violence against women in different conditions including during the COVID-19 crisis. In doing so, different reports and journal articles concerning violence against women were analyzed accordingly.

\section{Method of Analysis}

The collected data was analyzed flowing the qualitative data analysis technique such as categorization, classification, and summarization of data, transcription, and reformation of narratives, opinions, and experiences of the respondents. The secondary data on violence against women collected from news reports, journal articles, and reports of different organizations are analyzed in narratives and redrawn as per the qualitative research analysis techniques. Data and information from secondary sources are taken into consideration and logically merged with the qualitative and narrative findings to develop arguments and analysis along with the incorporation of the author's observations to discuss the nature and causes of the problem.

\section{FINDINGS AND DISCUSSION}

A total of 10 victims of violence against women were interviewed. All these respondents were helpful and cooperative though it is tough to talk about a sensitive issue of violence against women. The interviewed respondents have experienced different forms of violence such as domestic violence, child marriage, rape, Salish, stalking, and sexual harassment. Physical and mental torture due to familial crisis and dowry are found among the victims of domestic violence. Seven out of 10 respondents were married, 2 were unmarried and 1 was divorced. Three of them reported that they were injured because of the violence. In addition to this, 5 indepth interviews were conducted of victims' family members. These members talked about rape, acid attack, Salish, sexual harassment, and domestic violence due to dowry. Another 5 respondents who are working in women's rights and violence against issues and have expertise in the area were interviewed using KII.

Table 1. Profile of the Respondents

\begin{tabular}{|c|c|c|c|c|c|c|}
\hline \multicolumn{7}{|c|}{ In-depth Interview of Victims } \\
\hline $\begin{array}{c}\text { Interview } \\
\text { No. }\end{array}$ & Age & Education & Occupation & $\begin{array}{c}\text { Marital } \\
\text { Status }\end{array}$ & Nature of Violence & Remarks \\
\hline 1 & 32 & Primary & Housewife & Married & $\begin{array}{c}\text { Domestic Violence } \\
\text { (Physically and } \\
\text { Mentally Torture } \\
\text { due to Familial } \\
\text { Crisis) }\end{array}$ & Injured \\
\hline 2 & 17 & SSC & Housewife & Married & Child Marriage & \\
\hline 3 & 22 & HSC & Housewife & Married & Rape & \\
\hline
\end{tabular}




\begin{tabular}{|c|c|c|c|c|c|c|}
\hline 4 & 35 & Primary & Housewife & Married & Salish & \\
\hline 5 & 28 & Graduate & $\begin{array}{l}\text { Private } \\
\text { Service }\end{array}$ & Married & $\begin{array}{c}\text { Domestic Violence } \\
\text { (Physically and } \\
\text { Mentally Torture } \\
\text { due to Familial } \\
\text { Crisis) }\end{array}$ & Injured \\
\hline 6 & 17 & $\mathrm{SSC}$ & Housewife & Married & Child Marriage & \\
\hline 7 & 25 & SSC & Housewife & Divorced & Salish & \\
\hline 8 & 17 & SSC & Student & Unmarried & Stalking & \\
\hline 9 & 20 & HSC & Student & Unmarried & $\begin{array}{c}\text { Sexual Harassment } \\
\text { via Social Media }\end{array}$ & \\
\hline 10 & 24 & Primary & Housewife & Married & $\begin{array}{l}\text { Domestic Violence } \\
\text { (Physically and } \\
\text { Mentally Torture } \\
\text { due to Dowry) }\end{array}$ & Injured \\
\hline \multicolumn{7}{|c|}{ In-depth Interview of Victim's Family Members } \\
\hline $\begin{array}{c}\text { Interview } \\
\text { No. }\end{array}$ & \multicolumn{3}{|c|}{ Relation with the Victim } & \multicolumn{3}{|c|}{ Nature of Violence } \\
\hline 1 & \multicolumn{3}{|c|}{ Parent } & \multicolumn{3}{|c|}{ Rape } \\
\hline 2 & \multicolumn{3}{|c|}{ Brother } & \multicolumn{3}{|c|}{ Acid Attack } \\
\hline 3 & \multicolumn{3}{|c|}{ Parent } & \multicolumn{3}{|c|}{ Sexual Harassment } \\
\hline 4 & \multicolumn{3}{|c|}{ Sister } & \multicolumn{3}{|c|}{ Salish } \\
\hline 5 & \multicolumn{3}{|c|}{ Parent } & \multicolumn{3}{|c|}{ Domestic Violence due to Dowry } \\
\hline
\end{tabular}

Source: In-depth Interview, 2021

In the context of a global pandemic, COVID-19, the situation of violence against women worsens in many indicators because of the crisis that has an enormous impact in almost all spheres of lives. Different reports are showing a spike in the number of violence against women all over the world.

According to the recent data of BRAC cited in a news report, there were more cases of violence against women than in 2019 handled by BRAC's 410 Human Rights and Legal Aid Services in the first 10 months of 2020. BRAC states that 25,607 complaints of gender-based violence were received by the mentioned Human Rights and Legal Aid Services (Dhaka Tribune, 2020c). According to community-based women's groups of BRAC, Polli Shomaj (2020), there was a rise in the incidents of Violence against Women in the year 2020 than 2019 (Dhaka Tribune, 2020c). The same report states that Child Marriage is one of the major violence against women and girls provoked by the pandemic situation. Polli Shomaj (2020) indicates that a total of 371 child marriages were prevented in 2019 whereas 646 child marriages were prevented from January to September 2020. It clearly shows a spike in the cases of child marriage in 2020 compared to 2019.

A parent of a girl who was recently married stated that they have no way to maintain the expenses of education of their girl child. He claims that it is less expensive to get a good groom for a girl child rather than a fully grown and adult woman in terms of dowry. An analysis of the findings suggests that poverty and economic issues are some of the contributing factors in the spike of child marriage during the COVID-19 crisis. Parents have reported that they had seen the early marriage of their girl child as a way of reducing the economic burden, securing the future 
of their girl child from financial aspects, and ensuring the safety of their girl child from stalking and sexual harassment. From the victims 'point of view, it is tough for them to take such responsibility of maintaining household responsibilities that comes along with the marriage. Newly married girls have also claimed that they want to study further. But the corona situation and school closure have made it obvious for them to get married. Early marriage leads to early pregnancy in such an age when it is risky for the mother and child. One of the respondents interviewed is found pregnant in the six months of her marriage. According to the experts interviewed in this study, it is very common in rural areas. It risks the lives of the early married girls. Regular medical attention is needed in these cases. At the same time, experts have also claimed that having little knowledge on sexual, reproductive health, and nutritional issues, they fall in great danger in many terms.

A critical analysis of the data regarding rape, gang rape, attempt to rape, murder after rape, suicide because of rape, domestic violence against women, dowry-related violence against women, acid violence against women, violence against women instigated by Salish \& Fatwa, stalking and sexual harassment, and violence against women who work as domestic workers complied by ASK (2020) based on reports of different national newspapers, online news portals, and their database and documents show a devastating picture of violence against women in the middle of the Covid-19 crisis.

Report of ASK (2020) shows that from January to November 2020, a total of 1546 women and girls were raped among which 123 were raped, 303 were gang-raped, 51 were murdered after raped, and 14 committed suicide after being raped. Among 1546 rape incidents, 1082 cases were filed. Data of ASK (2020) also shows that a total of 311 were attempted to be raped. Among them, 4 were murdered after attempted to rape, 3 committed suicide to suicide after attempted to rape, and 193 cases were filed against the 311 attempted to rape incidents.

In addition to this, in a webinar, ASK (2020) reports that at least 583 women were raped whereas 198 of them gang-raped from January to October 2020 (Dhaka Tribune, 2020b). The same presentation at the webinar shows that from January to October 2020, 463 women were raped, 79 were gang-raped, 25 were murdered after rape, 141 were victims of an attempt to rape, 7 rape victims committed suicide after being raped. No rape victims were agreed to talk about their severity and pain. But one of the parents of victims interviewed under this study shared the stigma and pain that they are facing. In traditional society, rape victims are often blamed for their rape. People often stigmatize the victim. Respondents also claimed that it becomes difficult for the victim to appear in public life. One of the parents interviewed said that people find it shameful for them to be the victim. In many cases, marriage proposals are made for the victim woman or girls with the perpetrators. One respondent claimed that they were offered a marriage proposal for his daughter with the perpetrator as a form of settlement or negotiation.

There has been a discussion on 'rape culture' in Bangladesh both in the development and academic arena. Rape culture refers to circumstances where rape is prevalent and in which sexual violence against women is excused in popular culture and often normalized (Women's and Gender Center, 2021). According to Women's and Gender Center (2021), rape culture is perpetuated through the objectification of women's bodies, the use of misogynistic language, and the glamorization of sexual violence. Findings from the interview of development professionals working on women's rights issues show that the overall condition of women's rights issues and the secondary position compare to their male counterparts and marginal condition of women in the society are broadly responsible for the situation. Findings also suggest that 'toxic masculinity, victim-blaming, sexist representation of women's body and sexuality in media, 
sexual harassment and stalking tolerance by the victim, socialization of men's sexuality as dominant and aggressive are some of the influencing factors behind the spike in rape and raperelated violence against women in Bangladesh.

Women have also experienced violence in their household during the COVID- 19 crisis. Domestic Violence is a common form of violence against women in Bangladesh. The data presented and discussed above shows the terrifying condition of the nature and severity of violence that women are facing in Bangladesh in the last few years. Forms of domestic violence include torture by the husband, torture by the husband's family, murder by the husband, murder by the husband's, murder by own family, and torture by own family members.

Data compiled by ASK (2020) shows that 554 were subjected to domestic violence. Among them, 45 were tortured by husband, 17 were tortured by husband's family, 240 were murdered by husband, 71 were murdered by husband's family members, 56 were murdered by own family, 35 were tortured by own family, and 90 committed suicide. Data shows that 275 cases were filed against 554 incidents of domestic violence against women from January to December 2020.

Manusher Jonno Foundation (MJF) has conducted a telephone survey among 1 million women in 2020 which is presented in a news report. The report suggests that 40,000 suffered domestic violence in the last 6 months whereas $40 \%$ facing domestic violence for the first time in their lives (Dhaka Tribune, 2020a). MJF also reports that $47 \%$ of the total number of women who faced domestic violence were mentally abused. Added to this, 30\% have experienced physical violence, MJF reports.

An analysis of the interview of victims of domestic violence, family members of the victim, and professionals working on violence against women under this study show that age at marriage, the tendency of early marriage and difference between the age of husband and wife, patriarchal attitude, 'toxic' masculinity, the feminine and passive mentality of the victims, number of children, decision making power within the household, financial dependency, dowry, culture of tolerance, not getting help from parents, poverty, social and cultural approval of wifebeating are some of the contributing factors of domestic violence against women in Bangladesh. The COVID-19 has its implication with regards to domestic violence. It is found that even working women have started to experience domestic violence during the prolonged lockdown of COVID-19 after their confinement within the four walls of the house. It is also reported that mental torture also is a common form of domestic violence in a pandemic situation.

Physical torture, absconded from husband's house, suicide after physical torture, killing after physical torture are major forms of dowry-related violence occurring in 2020, according to ASK (2020). ASK (2020) shows that 218 dowry-related violence occurred from January to December 2020. Among them 99 were physically tortured, 12 were absconded from their husband's house, 18 committed suicide after physically tortured, 89 were killed after physical torture. Respondents claimed that women are often forced by their husband or husband's family members to bring the dowry money. Another respondent claimed that her husband and motherin-law used to torture her as she failed to bring dowry money as committed.

As mentioned and discussed previously, acid violence is a common form of violence against women in Bangladesh. Over the years, legal measures were developed and placed which resulted in the reduction of such incidents in recent years compared to the early years of horrific acid attacks on women in Bangladesh. Despite the improved situation, 2020 has witnessed 27 incidents of acid attacks on women. ASK (2020) report shows that family disputes, land disputes, refusal of the proposal of love affairs, refusal of the proposal of sexual relationship, 
enmity, intention to divorce the husband, and asking for reimbursement are some of the reasons behind the acid attack on women. The same report of ASK (2020) shows that 27 women were the victim of acid attacks in 2020. Among 27 incidents, 2 women died and only 7 cases were filed from January to December 2020.

Salish and Fatwa are used commonly in Bangladesh for local arbitration. Rural women, particularly women belonging to the lower social and economic background are vulnerable to Salish and Fatwa. ASK (2020) shows that 8 such incidents occurred where women were subjected to experience stigma, physical and mental torture, and severe sufferings because of the violence instigated by Salish and Fatwa from January - November 2020. Out of 8 victims, 4 were socially boycotted, 2 were mentally and physically tortured, and 2 were forced to get married to the perpetrator or divorced from her spouse. The same report also shows that 4 cases were filed and 1 committed suicide because of the Salish and Fatwa. The findings of this study show that in most cases, decisions are often taken against women without giving them the position to defend themselves. Salish has been found even in case of rape settlement or negotiation where the powerful ones try to establish their opinion over the less powerful individual. In most of the cases, as reported, the perpetrator holds a powerful position and influences the decision in their favor.

Women who work as domestic workers are one of the most affected groups who experience severe forms of violence against women. Data compiled by ASK (2020) shows that 45 women who used to work as domestic workers experienced different types of violence such as physical torture, rape, murder after rape, suicide, and death. From January to December 2020, 19 were physically abused or tortured, 8 were raped, 1 was murdered after being raped, 2 committed suicide, and 15 were dead due to different types of torture including physical torture. Total 31 cases are found to be filed out of 45 from January to December 2020.

Women who work as domestic worker belongs to the poorer section of the society. They are often more vulnerable in the COVID-19 pandemic. During such a crisis, earning the basics is a challenge for them. As COVID-19 has a serious impact on the economy, women who work as domestic workers face much more difficulties in different layers. They have concerns about their safety and security. But the urge for earning livelihood makes them more vulnerable comparatively. Added to this violence against domestic workers did not gain sufficient media coverage and overlooked in massive level advocacy. Bangladesh adopted a Domestic Workers Protection and Welfare Policy (DWPWP) in 2015 with 16 provisions for the improvement of more than 1.3 million domestic workers (Oxfam International, 2020). Effective implementation of the provisions of DWPWP will help to eradicate the abuse and exploitation of domestic workers including women workers and promote their rights, safety, and formal recognition.

Even in 2020, the number of incidents concerning stalking and sexual harassment continues as well. Reports of different newspapers, online news portals, and non-government organizations show a devastating picture of the impact of sexual harassment on girls.

It was thought that because of the limited social mobility and distancing as part of COVID-19 health measures, there is a less likely chance of sexual harassment and stalking. But different reports of newspapers and data compiled by different organizations show a different picture. According to ASK (2020) from January to December 2020, a total of 307 individuals including 201 females and 106 males were subjected to be victimized by the consequences of different forms of violence related to stalking and sexual harassment. Among 307, 14 female victims committed suicide and 3 attempted suicide, 3 female and 11 male were murdered due to protesting against the perpetrator, 172 female and 5 male assaulted by the stalkers, and 9 female 
and 90 male were injured because of the torture by the stalkers and perpetrators. Factors such as 'toxic masculinity, victim-blaming, sexist representation of women's body and sexuality in media, sexual harassment and stalking tolerance culture and attitude by the victim, socialization of men's sexuality as dominant and aggressive are behind the spike in the incidents of stalking and sexual harassment in Bangladesh.

Violence against Women (VAW) has enormous health, social and economic impacts on the victims and society as well. The analysis of the findings of this study leads to a discussion on how it has consequences on women's lives. Victims, their family members, and professionals working on women's rights issues reported that there is a huge cost of treatment and rehabilitation of the victims of violence against women. Women who were raped and victims of acid attacks lost their jobs and livelihood. The victim cannot search or approach for a new or alternative way of livelihood because of the social stigma. Sometimes, victim women become homeless resulting from the rejection of husband and stigma. It is also reported that the victim faces enormous rejection, humiliation, blaming, and stigma in family and society. As a result, they are often rejected from and abandoned by their family, and community as well. This situation creates a long-term impact on women's lives hindering their acceptability and access in the community and society. Women's and girls' education are also affected by their vulnerable condition. Violence like sexual harassment, stalking, and sexual violence are often reported and presented insensitively by the media. In the case of domestic violence, the whole issue is considered as private and personal matter leads to victim-blaming when it is revealed publicly. The health impact of such violence against women is often more dangerous. Different forms of violence are causing death, loss of eye-sight and hearing, and loss of internal and external organs. It also has serious implications on reproductive and sexual health issues. Unwanted pregnancy, death due to early pregnancy, sexually transmitted diseases are also common among the affected women. Social, economic, and health consequences of violence against women often lead to fatal outcomes including suicide and extreme depression by the victims. Issues like financial deprivation, poor access to and control over resources and assets, access to and control over the decision making process, access to education, training, and life-skill, and orientation with the public life are some of the cross-cutting factors influencing violence against women and women's safety are found in this study.

The discussion and analysis of the findings show that how women are facing horrific outcomes of different types of violence against women even in the middle of a global pandemic and one of the biggest humanitarian crises instigated by COVID-19. The actual situation is much more critical as all of the incidents of violence against women are not reported. Lockdown and limited social mobility made it crucial for the victims because of the complicated situation of social and financial difficulties during the COVID-19 crisis.

\section{CONCLUSION}

In the middle of a global crisis and health emergency, it is understandable to us that the COVID19 does limit the prevalence of violence against women rather it has become obvious in Bangladesh. In a complex social sphere, where women have to deal with the rigid unjust social norms promoting and perpetuating patriarchy and gender discrimination, violence against women makes it more vulnerable for them in the context of the pandemic. The discussion has made it obvious for us to better address the problem and find a timely solution to combat such violence against women in the coming days. Issues like domestic violence, sexual harassment, rape, violence instigated by Salish and Fatwa, and child marriage are deeply rooted in the socio- 
cultural aspects. It is necessary to understand the underlying contributing factors that have led to the spike of violence against women during the pandemic and must be addressed in all layers of action in combating such incidents. Data and findings of this study suggest that the actual number of such violence against women is higher than the reported incidents. All incidents are not reported and documented. There must be a change in the attitude of men towards women. Work must be done both on a short-term basis such as taking lawful action against the perpetrators and other measures and long term bases such as bringing a positive change in the unjust gender norms and women's marginalization in society to combat violence against women.

\section{REFERENCES}

Ain o Salish Kendra (ASK). (2020). Statistics on Human Rights Violations. Ain O Salish Kendra (ASK). Retrieved from https://www.askbd.org/ask/statistics-on-human-rightsviolations/?_page=3

Corona Info. (2020). Coronavirus Disease 2019 (COVID-19) Information Bangladesh. Corona Info. Retrieved from https://corona.gov.bd

Crowell, N. A., \& Burgess, A. W. (1996). Understanding Violence Against Women. National Academy Press. Retrieved from https://www.ojp.gov/pdffiles1/Digitization/162272NCJRS.pdf

Dhaka Tribune. (2017, October 25). Sultana Kamal: $87 \%$ of women face domestic violence in Bangladesh. Dhaka Tribune. Retrieved from https://www.dhakatribune.com/bangladesh/2017/10/25/sultana-kamal-87-women-facedomestic-violence-bangladesh

Dhaka Tribune. (2018, December 6). Research shows 66\% of Bangladeshi women are victims of domestic violence. Dhaka Tribune. Retrieved from https://www.dhakatribune.com/bangladesh/nation/2018/12/06/research-shows-66bangladeshi-women-are-victims-of-domestic-violence

Dhaka Tribune. (2020a, November 24). 16,000 women experienced violence at home first time amid Covid-19 pandemic. Dhaka Tribune. Retrieved from https://www.dhakatribune.com/health/coronavirus/2020/11/24/16-000-womenexperienced-violence-at-home-first-time-amid-covid-19pandemic/?fbclid=IwAR0OrJe_FADY7fwJK5KNh4ixxMKpXbthK4MnmhYk_iJnPQL q9o7ftAYTmcU

Dhaka Tribune. (2020b, November 26). Speakers: Spike in gender-based violence amid Covid19 pandemic. Dhaka Tribune. Retrieved from https://www.dhakatribune.com/bangladesh/2020/11/26/speakers-spike-in-gender-basedviolence-amid-covid-19-pandemic

Dhaka Tribune. (2020c, December 1). Study: Gender-based violence in Bangladesh up by $24 \%$ amid Covid-19 pandemic. Dhaka Tribune. Retrieved from 
https://www.dhakatribune.com/health/coronavirus/2020/12/01/study-gender-basedviolence-on-the-rise-amid-covid-19-pandemic

Ellsberg, M., \& Heise, L. (2005). Researching violence against women: a practical guide for researchers and activists.

Hossen, M. A. (2014). Measuring Gender-based violence: Results of the Violence Against Women (VAW) Survey in Bangladesh. Retrieved from https://unstats.un.org/unsd/gender/Mexico_Nov2014/Session\%203\%20Bangladesh\%20p aper.pdf

Human Rights Watch. (2020). "I Sleep in My Own Deathbed" Violence against Women and Girls in Bangladesh: Barriers to Legal Recourse and Support. In Save the Children's Resource Centre. Retrieved from https://resourcecentre.savethechildren.net/library/violence-against-women-and-girlsbangladesh-barriers-legal-recourse-and-support

Hossain, K. T., Imam, M. H., \& Khair, S. (2001). Males' Perception on Violence Against Women in Bangladesh (mimeo). Dhaka: British Council.

International Federation For Human Rights. (2020, November 24). Violence against women on the rise amid COVID-19 and rampant impunity. International Federation for Human Rights. Retrieved from https://www.fidh.org/en/region/asia/bangladesh/violence-againstwomen-on-the-rise-amid-covid-19-and-rampant-impunity

Latifee, E. H., \& Hossian, M. S. (2020, August 22). Covid-19 pandemic: Choosing between job and entrepreneurship. The Business Standard. Retrieved from https://www.tbsnews.net/thoughts/covid-19-pandemic-choosing-between-job-andentrepreneurship-122680

Mahtab, N. (2012). Women, Gender and Development: Contemporary Issues. A H Development Publishing House.

Odhikar. (2020). Statistics on Violence against women. Odhikar; Dhikar. Retrieved from http://odhikar.org/statistics/statistics-on-violence-against-women/

Oxfam International. (2020). Securing Protection for Domestic Workers in Bangladesh. Oxfam Digital Repository; Retrieved from https://oxfamilibrary.openrepository.com/bitstream/handle/10546/621102/cs-securingprotection-domestic-workers-171120-en.pdf?sequence $=1 \&$ isAllowed=y

Prothom Alo. (2021, March 12). Bangladesh ranks 4th in violence against women by intimate partner. Prothomalo. Retrieved from https://en.prothomalo.com/bangladesh/bangladeshranks-4th-in-violence-against-women-by-intimate-partner 
Relief Web. (2017, September 21). Questions and Answers: EU-UN Spotlight Initiative to eliminate violence against women and girls. ReliefWeb. Retrieved from https://reliefweb.int/report/world/questions-and-answers-eu-un-spotlight-initiativeeliminate-violence-against-women-and

Runyan, A. (2018). What Is Intersectionality and Why Is It Important? American Association of University Professors. Retrieved from https:/www.aaup.org/article/whatintersectionality-and-why-it-important

Shuvro, R. A., \& Talukder, Md. M. (2020). Impact of "COVID-19" on the Life of Destitute People: A Soft-Measurement in Bangladesh. Bangladesh Journal of Multidisciplinary Scientific Research, 2(2), 17-31. https://doi.org/10.46281/bjmsr.v2i2.723

The Daily Star. (2019, November 25). Violence against women cannot be normalised. . Retrieved from https://www.thedailystar.net/editorial/news/violence-against-womencannot-be-normalised-1831597

The Financial Express. (2020, June 25). 13pc people lost jobs due to Covid-19 pandemic: BIDS survey. The Financial Express. Retrieved from https://thefinancialexpress.com.bd/economy/bangladesh/13pc-people-lost-jobs-due-tocovid-19-pandemic-bids-survey-1593064095

The United Nations (UN). (2016). Gender Statistics - Violence against Women. The United Nations Statistics Division. Retrieved from https://unstats.un.org/unsd/gender/vaw/

UN Women. (2010). The Life Cycle and Violence. Retrieved from https://www.endvawnow.org/en/articles/ 298-the-life-cycle-and-violence.html

UN Women. (2021). Global Database on Violence against Women. UN Women. Retrieved December 2020, 12, from https:/levaw-globaldatabase.unwomen.org/pt/countries/asia/bangladesh

United Nations Development Programme (UNDP). (2020). Coronavirus disease COVID-19 pandemic. UNDP. $\quad$ Retrieved from https://www.undp.org/content/undp/en/home/coronavirus.html

Women's and Gender Center. (2021). Rape Culture. Marshall University. Retrieved from https://www.marshall.edu/wcenter/sexual-assault/rape-culture/

\section{Copyrights}

Copyright for this article is retained by the author(s), with first publication rights granted to the journal. This is an open-access article distributed under the terms and conditions of the Creative Commons Attribution license (http://creativecommons.org/licenses/by/4.0/). 